\title{
PROTOTIPE SISTEM PEMETAAN SNI, LEMBAGA PENILAIAN KESESUAIAN (LPK) DAN SERTIFIKAT SNI
}

\author{
SNI, Conformity Assessment Bodies and SNI Ceritificate Online Mapping Prototype \\ System
}

\author{
Ramita Utami dan Adlin Ichsan
}

Badan Standardisasi Nasional, Gedung I BPPT, Jl. MH Thamrin No. 8, Jakarta Pusat

Email: ramita@bsn.go.id

\begin{abstract}
Abstrak
Badan Standardisasi Nasional (BSN) berupaya meningkatkan efisiensi dan efektivitas kerja, dan peningkatan kualitas layanan kepada masyarakat. Salah satu upaya untuk mendukung hal tersebut ialah dengan menyediakan informasi yang valid dan mudah diakses oleh masyarakat terkait pemanfaatan SNI di seluruh Indonesia. Upaya tersebut dilakukan dengan memanfaatkan perkembangan teknologi, khususnya teknologi informasi. Data yang digunakan dalam penelitian ini berupa data primer maupun sekunder yang terkait dengan Standar Nasional Indonesia (SNI), Lembaga Penilaian Kesesuaian (LPK) maupun Sertifikat SNI yang telah dikeluarkan. Data-data tersebut dikompilasi dan ditampilkan dalam bentuk peta online berbasis Sistem Informasi Geografis. Peta online dapat dimanfaatkan untuk pencarian informasi LPK terkait lokasi, kompetensi,kesiapan peralatan dan laboratorium. Selain itu juga untuk pencarian informasi tentang produk-produk yang telah mendapatkan sertifikat SNI.

Kata kunci: peta online, lembaga penilaian kesesuaian (lpk), sertifikasi sni.
\end{abstract}

\begin{abstract}
National Standardization Agency of Indonesia (Indonesian: Badan Nasional Standardisasi, BSN) seeks to boost work efficiency and effectiveness and also to improve the quality of its public service. One of the efforts to support this is to provide valid and easy to access information related to the use of Indonesian National Standard (Indonesian: Standar Nasional Indonesia, SNI) throughout Indonesia. These efforts are carried out by utilizing the very rapid technological developments, especially information technology. The data used in this study are primary and secondary data related toSNI, Conformity Assessment Bodies (Indonesian: Lembaga Penilaian Kesesuaian, LPK) and the issued SNI certificate. The data is compiled and displayed in the form of an online map based on Geographic Information System. The map can be used to search for LPK information related to location, competency, equipments and laboratories readiness. In addition, you can also search for information about products that have received SNI certificates.
\end{abstract}

Keywords: online mapping, conformity assessment body, SNI certification

\section{PENDAHULUAN}

Perkembangan teknologi informasi saat ini berkembang sangat pesat sehingga perannya dalam birokrasi di pemerintahan menjadi salah satu syarat peningkatan pelayanan masyarakat. Perkembangan tersebut ditandai dengan kecepatan akses informasi yang cepat, valid dan mudah di berbagai pelayanan. Hal ini berakibat masyarakat lebih banyak berinteraksi pada perangkat teknologi informasi untuk mencapai berbagai tujuannya. Kebutuhan akan informasi SNI, sertifikat SNI dan LPK yang tersertifikasi tidak luput dari pemanfaatan teknologi informasi yang disediakan BSN guna meningkatkan pelayanan masyarakat. Faktanya BSN sudah menyediakan aplikasi terkait dengan informasi SNI, sertifikat SNI dan LPK yang tersertifikasi. Namun masyarakat masih menemui kesulitan dalam mengumpulkan informasi tersebut. Khususnya untuk kelompok pelaku usaha maupun investor, mengalami kesulitan dalam menemukan di daerah mana saja LPK yang tersertifikasi itu ada dan LPK mana saja yang telah memiliki sertifikat SNI. Aplikasi yang ada saat ini masih terpecah menjadi 3 (tiga) aplikasi untuk masing-masing informasi yaitu SNI, sertifikat SNI dan LPK yang tersertifikasi. Penggunaan 3 (tiga) aplikasi dalam mengumpulkan informasi dinilai sangat tidak efisien untuk kebutuhan masyarakat. Demi meningkatkan pelayanan kepada masyarakat, BSN termotivasi untuk membangun suatu sistem yang mudah, valid dan cepat dalam menjawab pelayanan terkait informasi SNI, sertifikat SNI dan LPK yang tersertifikasi dalam satu aplikasi pemetaan. Langkah awal yang dilakukan BSN untuk mewujudkan hal tersebut adalah dengan membuat prototipe. 


\section{TINJAUAN PUSTAKA}

\section{Standar Nasional Indonesia (SNI), Penilaian Kesesuaian dan Sertifikasi SNI \\ SNI adalah satu-satunya standar yang} berlaku secara nasional di Indonesia. SNI dirumuskan oleh Komite Teknis (dulu disebut sebagai Panitia Teknis) dan ditetapkan oleh BSN.Penilaian Kesesuaian mencakup kelembagaan dan proses penilaian untuk menyatakan kesesuaian suatu kegiatan atau suatu produk terhadap SNI tertentu. Penilaian kesesuaian dapat dilakukan oleh pihak pertama (produsen), pihak kedua (konsumen), atau pihak ketiga (pihak selain produsen dan konsumen), sejauh pihak tersebut memiliki kompetensi untuk memenuhi persyaratan yang ditetapkan oleh BSN.

Sesuai dengan UU No.20 tahun 2014, pelaksanaan tugas $\mathrm{BSN}$ di bidang penilaian kesesuaian ditangani oleh Komite Akreditasi Nasional (KAN) yang dibentuk oleh pemerintah untuk keperluan menjamin kompetensi pelaksana penilaian kesesuaian melalui proses akreditasi. KAN sebagai Badan Akreditasi Nasional mempunyai tugas untuk memberikan akreditasi kepada lembaga penilaian kesesuaian (Laboratorium Penguji, Labortaorium Kalibrasi dan Lembaga Sertifikasi). Lembaga Penilaian Kesesuaian yang telah diakreditasi oleh KAN mempunyai hak untuk menerbitkan sertifikat sesuai dengan lingkup akreditasinya.

Sertifikasi SNI merupakan proses sertifikasi bagi produsen yang akan mencantumkan tanda/logo SNI pada produknya. Produsen dapat mengajukan Sertifikasi SNI ini kepada Lembaga Sertifikasi Produk (LS-Pro) sebagai lembaga yang berhak menerbitkan sertifikat SNI. Proses Sertifikasi SNI ini harus memenuhi aspek administratif dan teknis sesuai SNI yang dirujuk. Apabila pemerintah telah menetapkan suatu produk waiib memiliki sertifikat SNI, maka produsen harus memenuhi kewajiban tersebut sebelum produknya diperdagangkan. Apabila pemerintah tidak/belum mewajibkan sertifikat SNI, maka produsen boleh menjual produknya tanpa tanda SNI. Namun jika produsen ingin mencantumkan tanda SNI pada produknya, produsen tetap harus mengajukan Sertifikasi SNI kepada LS-Pro.

\section{Sistem Informasi Geografis}

Sistem Informasi Georafis (Geographic Information System) merupakan suatu sistem informasi yang berbasis komputer, yang dirancang untuk bekerja dengan menggunakan data yang memiliki informasi spasial (bereferensi keruangan). Sistem ini mengcapture, mengecek, mengintegrasikan, memanipulasi, menganalisa, dan menampilkan data yang secara spasial mereferensikan kepada kondisi bumi (Prahasta, 2015).

SIG telah menjadi alat yang memiliki dampak positif dalam proses perencanaan berbasis komunitas dan pembuatan keputusan ilmiah untuk aktivitas pengembangan program. SIG merupakan sebuah sistem yang mampu membangun, memanipulasi dan menampilkan informasi yang mempunyai referensi geografis (Baros dan Stojanovic, 2015).

Prahasta (2015) menjelaskan secara prinsipnya data terdiri dari dua jenis dalam SIG, yaitu:

a. Data Spasial

Data spasial merupakan perwujudan nyata suatu daerah yang ada di permukaan bumi. Secara umum dipresentasikan dalam bentuk peta, gambar berformat digital dan disimpan dalam bentuk koordinat $\mathrm{x}, \mathrm{y}$ (vektor) atau dalam bentuk image (raster) yang mempunyai nilai tertentu.

b. Data Non Spasial

Data nonspasial merupakan data berupa tabel yang mana tabel tersebut memiliki isi informasi yang dimiliki oleh obyek dalam data spasial. Data itu berbentuk data tabular yang satu sama lain di integrasikan dengan data spasial yang ada.

\section{Application Programming Interface (API)}

Mengutip dari Jin, et al (2018) API adalah sebuah teknologi untuk memfasilitasi pertukaran informasi atau data antara dua atau lebih aplikasi perangkat lunak. API berperan sebagai pembawa pesan yang menerima permintaan pengguna dan memberitahu sistem apa yang harus dilakukan, lalu memberikan respons yang sesuai dengan permintaan tersebut. Ketika terjadi interaksi antara basis data aplikasi dengan gawai atau komputer, masing-masing sistem tersebut memiliki API yang memungkinkan untuk saling bertukar informasi. Dengan kata lain API adalah apa yang membawa informasi antara basis data aplikasi dan gawai pengguna untuk menyampaikan data dan menciptakan konektivitas antar sistem (Sirenden, 2016).

\section{METODE PENELITIAN}

Metode penelitian yang digunakan dalam penelitian ini ialah menggunakan metode SDLC (System Development Life Cycle) yang dilaksanakan dengan tahap-tahap sebagai berikut (Wahyudi, 2018):

a. Survei kebutuhan

Survei dilakukan dengan melakukan wawancara terhadap narasumber maupun 
dengan melakukan studi pustaka. Wawancara dilakukan terhadap narasumber internal BSN yang menangani pengembangan $\mathrm{SNI}$, penerapan $\mathrm{SNI}$ maupun akreditasi. Selain itu, wawancara juga dilakukan terhadap beberapa narasumber dari Lembaga penilaian kesesuaian (LPK).Studi pustaka dilakukan dengan analisis terhadap berbagai sistem informasi (aplikasi) yang ada di BSN yang terkait dengan SNI, akreditasi dan Sertifikasi SNI.

b. Penyusunan disain sistem

Pada tahap kedua dilakukan analisis terhadap hasil survey kebutuhan dan penyusunan desain sistem terhadap hasil analisis tersebut. Desain yang disusun meliputi, basis data, tampilan dan aplikasi.

c. Pembangunan aplikasi

Pembangunan aplikasi dilakukan dengan berpedoman kepada desain yang disusun pada tahap sebelumnya. Tahap ini memerlukan waktu yang paling panjang dalam pelaksanaan kegiatan ini.

d. Uji coba

Setelah tahap pembangunan aplikasi selesai, maka dilakukan uji coba untuk memastikan bahwa sistem berjalan dengan baik dan dapat diimplementasikan.

e. Implementasi sistem

Setelah melalui tahap uji coba dan perbaikan, maka dilakukan tahap implementasi sistem dan dapat dimanfaatkan oleh berbagai pihak terkait untuk memperoleh data dan informasi yang valid terkait SNI, LPK dan Sertifikat SNI.

f. Perawatan sistem

Sistem yang telah dibangun dan diimplementasikan tersebut memerlukan perawatan dan pengembangan sesuai dengan tuntutan dan kebutuhan yang setiap saat berkembang.

\section{HASIL DAN PEMBAHASAN}

\section{Survei kebutuhan}

Setelah melalui beberapa pertemuan dalam kegiatan rapat bersama antara bidang TI BSN dengan para sumber internal BSN yang setiap hari berinteraksi dengan data LPK, SNI dan Sertifikasi SNI didapatkan bahwa ada kebutuhan terkait penyampaian informasi berupa :

a. Akumulasi data LPK per-provinsi

b. Data LPK dengan ruang lingkup dan SNInya yang terdapat pada provinsi tertentu

c. Data SNI yang diterapkan pada LPK beserta ruang lingkupnya pada provinsi tertentu d. Data sertifikat SNI yang dikeluarkan pada LPK tertentu di provinsi tertentu

e. Data produk ber-SNI yang LPK-nya dapat dilacak lokasinya pada provinsi tertentu

Hasil analisis menunjukkan bahwa dari 40 aplikasi yang aktif di BSN disaring aplikasi mana saja yang mampu menampilkan data tersebut. Hasil dari analisis TI BSN diambil 3 aplikasi terkait, yaitu : SISPK, KANMIS dan Bangbeni. SISPK adalah aplikasi yang mampu menampilkan data SNI dan LPK. KANMIS adalah aplikasi yang mampu menampilkan LPK yang tersertifikasi KAN dan Bangbeni adalah aplikasi yang mampu menampilkan produk mana saja yang ber-SNI dan perolehan sertifikat SNI.

\section{Penyusunan Desain Sistem}

a. Desain Basis data

Untuk mengetahui lebih lanjut setiap entitas yang terlibat dan aliran data masuk dan keluar dari sistem, maka dilakukan penggambaran context diagram serta entity relationship diagramberdasarkan buku yang ditulis Indrajani (2015) seperti yang ditampilkan pada Gambar 1.

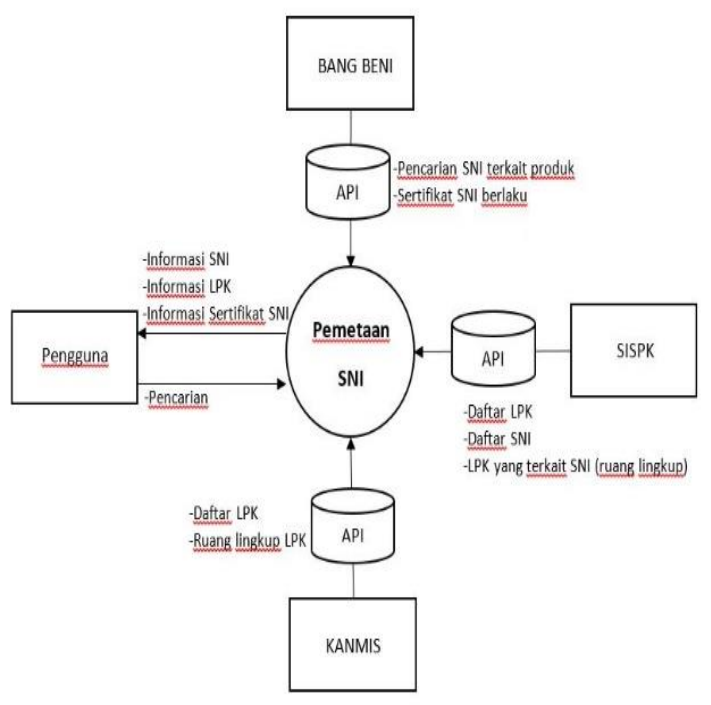

Gambar 1. Context Diagram Sistem

Berikut adalah entity relationship diagram(ERD) dari proses pemetaan SNI, LPK dan Sertifikat SNI. 


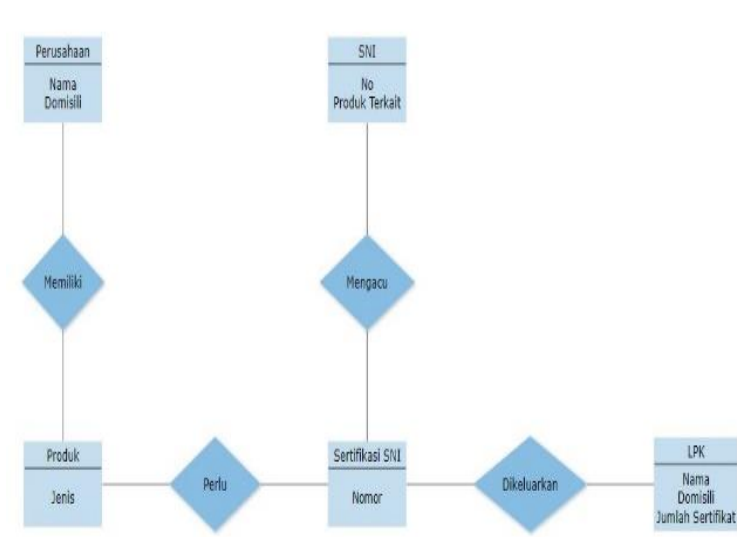

Gambar 2. ERD Sistem

b. Desain Aplikasi

Desain aplikasi yang digambarkan pada Pemetaan SNI, LPK dan Sertifikat SNI dilampirkan dalam bentuk diagram Enterprise Application. Adapun penggambaran besar aplikasinya adalah sebagai berikut :

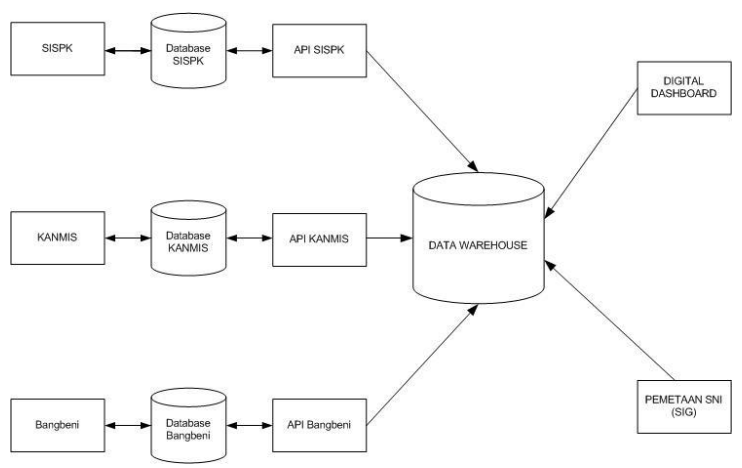

Gambar 3. Desain Aplikasi Sistem

Konsep data warehouse digunakan pada aplikasi Pemetaan SNI karena dinilai mampu menampilkan data sesuai kebutuhan (Rahardjo, 2015). Data yang masuk dalam data warehouse adalah berasal dari data tiga aplikasi yaitu, SISPK, KANMIS dan Bangbeni yang masing-masing saling berkomunikasi melalui teknologi API. Jika dijabarkan dalam diagram alur adalah sebagai berikut :

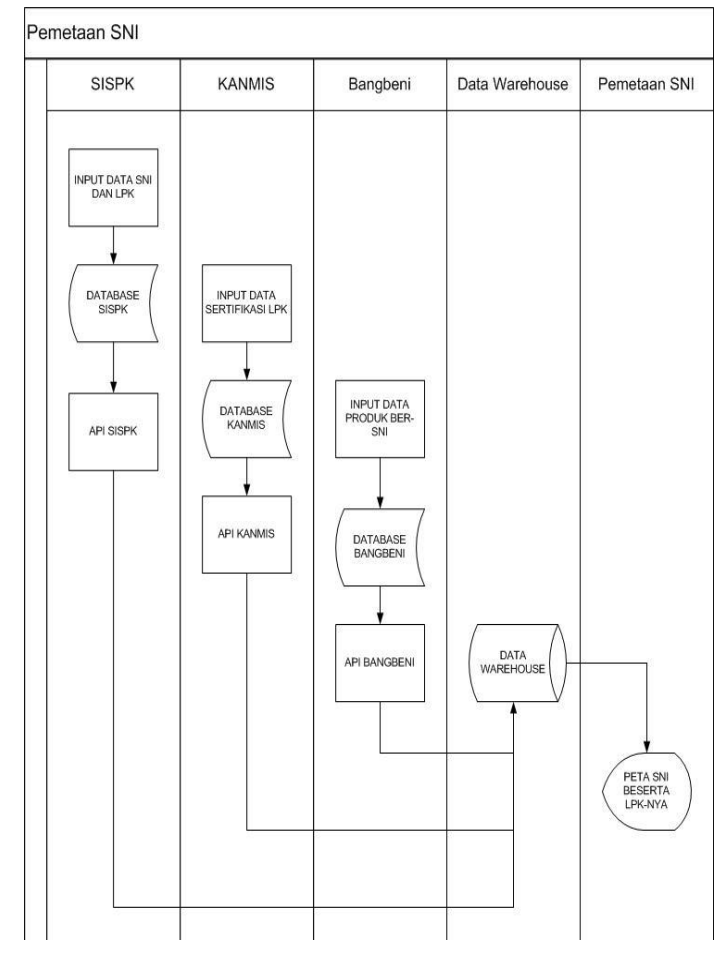

Gambar 4. Diagram alur Sistem

Adapun interaksi antara pengguna dengan aplikasi digambarkan dalam suatu diagram aktifitas sebagai berikut :

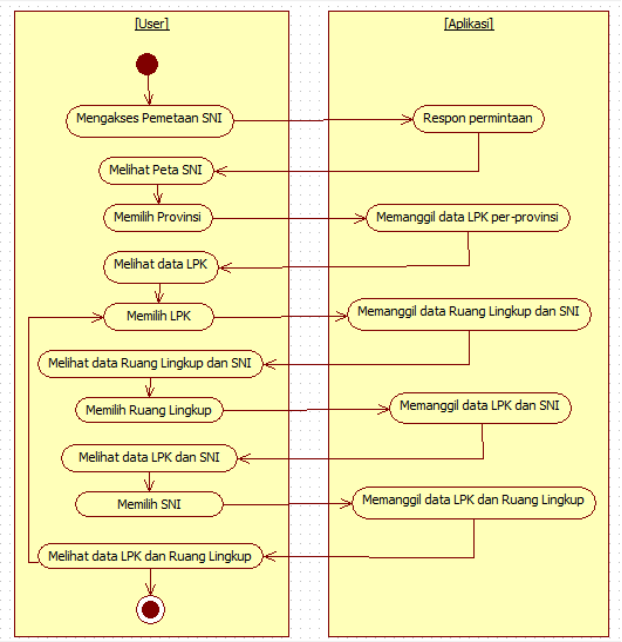

Gambar 5. Diagram Aktivitas Sistem

c. Desain Tampilan

Desain tampilan digambarkan dengan prototipe. Tampilan awal pada pemetaan SNI adalah tampilan peta Indonesiayang sudah dibagi dengan batas provinsi masingmasing sebagaimana terlihat pada Gambar 6. 


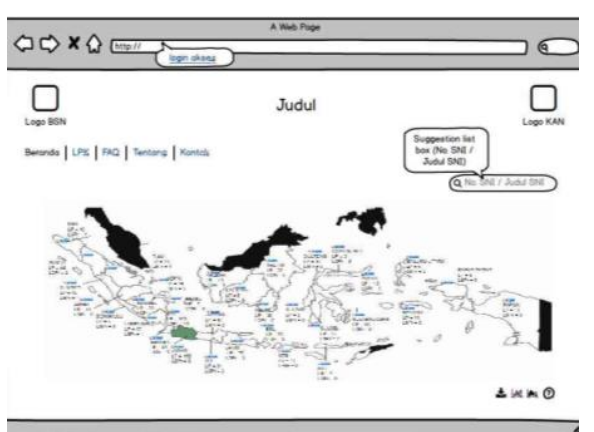

Gambar 6. Tampilan Peta Data Spasial

Pada masing-masing provinsi diletakan popup informasi untuk menampilkan data spasial jumlah LPK. Sedangkan tampilan untuk data non-spasial adalah sebagai berikut:

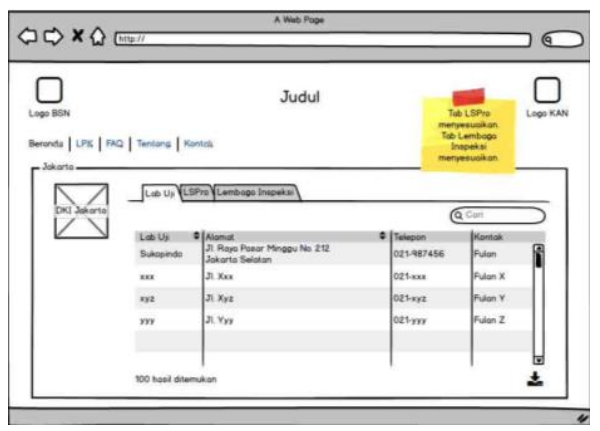

Gambar 7. Tampilan Data Non-spasial

Proses agar sampai pada tampilan di atas adalah dengan klik pada salah satu provinsi. Data yang tampil diharapkan juga berupa diagram agar dapat mempermudah dalam pengolahan data yang berfungsi sebagai pengambilan keputusan sebagaimana terlihat pada Gambar 8.

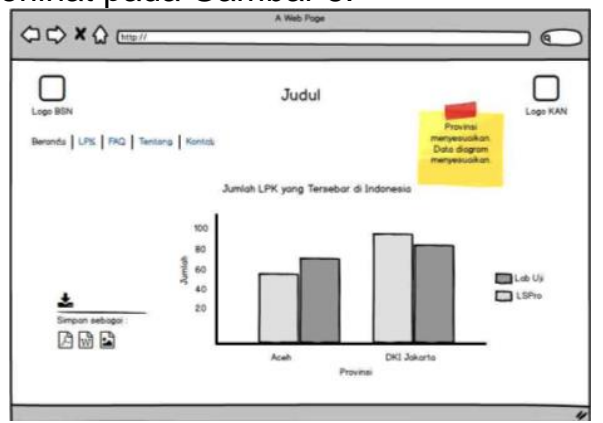

Gambar 8. Tampilan data dalam bentuk diagram

\section{Pembangunan Aplikasi}

Prototipe yang telah dibuat adalah acuan dalam pembangunan aplikasi. Dasar pembuatan protipe dibuat dari sisi user dan admin. Prototipe dari sisi user banyak menampilkan informasi dalam bentuk gambar (peta wilayah), tabel dan diagram. Sedangkan prototipe dari sisi admin menampilkan informasi dalam bentuk tabel dan form. Proses pembangunan hingga saat ini masih berjalan. Sistem prototipe mengacu pada penelitian Akbar (2015).

\section{Uji Coba}

Sistem yang berhasil dibuat kemudian diuji dengan metode uji Black Box. Menurut Nidhra dan Dondeti (2012) metode uji Black Box memfokuskan pada keperluan fungsional dari software. Pengujian ini bertujuan untuk menguji fungsi-fungsi khusus pada perangkat lunak yang dibuat. Skenario pengujian dapat dilihat seperti pada Tabel 1.

Tabel 1 Pengujian dengan Metode Black Box

\begin{tabular}{|c|c|c|c|c|}
\hline No & $\begin{array}{l}\text { Komponen } \\
\text { yang Diuji }\end{array}$ & Skenario Pengujian & Hasil yang Diharapkan & Kesimpulan \\
\hline \multirow[t]{2}{*}{1} & \multirow[t]{2}{*}{ Menu Login } & $\begin{array}{l}\text { Memasukkannama } \\
\text { pengguna dan kata } \\
\text { sandi yang benar }\end{array}$ & Mengalihkan ke halaman utama & Valid \\
\hline & & $\begin{array}{l}\text { Memasukkan nama } \\
\text { pengguna dan kata } \\
\text { sandi yang salah }\end{array}$ & $\begin{array}{l}\text { Menampilkan pesan pop-up "nama } \\
\text { pengguna dan/atau kata sandi } \\
\text { salah" }\end{array}$ & Valid \\
\hline \multirow[t]{3}{*}{2} & \multirow{3}{*}{$\begin{array}{l}\text { Menu } \\
\text { Halaman } \\
\text { Utama }\end{array}$} & $\begin{array}{l}\text { Mengklik daerah di } \\
\text { peta }\end{array}$ & $\begin{array}{l}\text { Menampilkan jumlah dan nama LPK } \\
\text { yang ada di daerah tersebut }\end{array}$ & Valid \\
\hline & & Mengklik nama LPK & Membuka menu data LPK & Valid \\
\hline & & $\begin{array}{l}\text { Mengetikkan nomor } \\
\text { atau judul SNI pada } \\
\text { kotak pencarian }\end{array}$ & $\begin{array}{l}\text { Menyoroti daerah dengan LPK yang } \\
\text { berhubungan dengan SNI tersebut }\end{array}$ & Valid \\
\hline 3 & $\begin{array}{l}\text { Menu Data } \\
\text { LPK }\end{array}$ & $\begin{array}{l}\text { Mengklik tab Lab } \\
\text { Uji/LS Pro/Lembaga } \\
\text { Inspeksi }\end{array}$ & $\begin{array}{l}\text { Menampilkan daftar Lab Uji/LS } \\
\text { Pro/Lembaga Inspeksi di daerah } \\
\text { tersebut }\end{array}$ & Valid \\
\hline
\end{tabular}




\section{Implementasi Sistem}

Implementasi aplikasi pemetaan SNI ditujukan kepada pengguna internal dan eksternal BSN. Pengguna internal BSN diantaranya para staf BSN yang bekerja sebagai admin aplikasi, untuk memantau kinerja dari aplikasi. Selain itu digunakan juga oleh staf perumusan yang menjadi verifikator ataupun updater untuk memantau validasi data LPK yang tampil pada aplikasi. Pengguna eksternal BSN yang merasakan langsung implementasi aplikasi pemetaan SNI adalah LPK dan para produsen yang ingin mensertifikasi produk atau laboratoriumnya. Implementasi juga dapat dirasakan masyarakat dan investor yang ingin mensertfikasi produk mereka sesuai SNI pada wilayah yang terjalin kerja sama investasi dengan pemerintah Indonesia.

\section{Perawatan Sistem}

Aplikasi pemetaan dibangun dengan spesifikasi teknis bahasa pemrogaman PHP menggunakan framework Codelgniter. Basis data yang digunakan adalah MySQL. Teknologi API digunakan pada masing-masing dari 3 aplikasi terkait yaitu SISPK, KANMIS dan Bangbeni. Perawatan akan dijalankan oleh PUSDATIN (Pusat Data dan Sistem Informasi) BSN. Perawatan aplikasi diserahkan pada bidang SITKD (Sistem Informasi dan Tata Kelola Data), sedangkan perawatan infrastruktur akan diserahkan pada bidang IKI (Infrastruktur dan Keamanan Informasi). Monitoring dan evaluasi, dan perawatan basis dataakan dilakukan sesuai prosedur SMKI BSN.

\section{KESIMPULAN}

Sistem Pemetaan SNI, LPK dan Sertifikat SNI ini diharapkan mampu menyediakan informasi yang valid dan mudah diakses oleh masyarakat terkait pemanfaatan SNI di seluruh Indonesia. Peta online dibangun dengan basis situs web yang mampu diakses setiap saat dan dimana pun. Dengan adanya peta online ini, pelaku usaha dapat mengetahui $\mathrm{SNI}$ yang berhubungan dengan produk miliknya yang ingin disertifikasi serta informasi LPK di daerahnya yang dapat memberikan sertifikat SNI terkait dengan data terkini dan valid. Demikian pula dengan informasi yang berhubungan dengan LPK dan SNI yang telah diterapkan oleh LPK tersebut. Sehinggaberdasarkan data-data tersebut nantinya dapat diketahuitingkat pemanfaatan SNI di Indonesia.

\section{DAFTAR PUSTAKA}

Akbar, M. (2015). Pengembangan Sistem Menggunakan Model Prototype Pada Sistem Informasi Pemetaan Potensi Pertanian Berbasis Web. Universitas Islam Negeri Sunan Kalijaga.

Baros, T., \& Stojanovic, T., 2015. Geographic Information System (GIS) in Mapping of Mine Suspected Area in the Republic of Serpska. Global Journals Inc.

Indrajani (2015). Database Design. Jakarta: Elex Media Komputindo.

Jin, B., Sahni, S. \& Shevat, A. (2018). Designing Web APIs: Building APIs That Developer Love. New York: O'Reilly Media.

Nidhra, S., \& Dondeti, J. (2012). Black box and white box testing techniques-a literature review. International Journal of Embedded Systems and Applications (IJESA), 2(2), 29-50.

Prahasta, E. (2015). Mengelola Peta Dijital. Mendapatkan dan Mengelola Peta Dijital di Internet yang Penting dan Gratis. Informatika.

Prahasta,E. (2015). Sistem Informasi Geografis, Konsep-konsep Dasar, King IT Bookstore.

Rahardjo, D (2015). Prototipe Sistem Informasi Geografis Fasilitas Kesehatan di Kota Cirebon Berbasis Web. Jurnal Teknik Informatika dan Sistem Informasi.

Sirenden, B. (2016). Buat Sendiri Aplikasi Petamu Menggunakan Codelgniter Dan Google Maps API - CD. Andi Publisher.

Wahyudi, A. (2018). Perancangan Sistem Menggunakan Metode SDLC. 